\title{
Shoulder adhesive capsulitis, treatment with oxygen ozone: Technique and results
}

\author{
Giulio Peretti \\ SIOOT Oxigen Ozone Therapy Scientific Society, Gorle (BG), Italy
}

\begin{abstract}
Adhesive capsulitis of the shoulder, also known as frozen shoulder, is a condition characterized by a reduction in the arc of active and passive motion of the joint in the presence of essentially normal radiographic tests, except for the possible finding of osteopenia or calcific tendinitis. It is a condition with an uncertain etiology, characterized by the spontaneous onset of pain. From March 2015 to March 2016, 10 patients with adhesive capsulitis were treated with a cycle of intra-articular and subcutaneous infiltrations. Of these, 6 patients were female, of 49.3 average age (min $40-\max 59$ ) and 4 male, and 4 were male, of 56.7 average age ( $\min 48$ - $\max 65)$; the average age of all participants was 52.3 (min 40 - $\max 65$ ). The dominant limb was affected in seven cases, while in three, the non-dominant limb was affected. Oxygen-ozone treatment in adhesive capsulitis proved to be extremely effective; the absence of side effects has proven the safety of its use. A comparison with other types of treatment demonstrates a similar, and perhaps greater efficacy with no risks and side effects such as are present in the others. Further studies are necessary to confirm the validity of this technique.
\end{abstract}

\section{Introduction}

Adhesive capsulitis of the shoulder, also known as frozen shoulder, is a condition characterized by a reduction in the arc of active and passive motion of the joint in the presence of essentially

Correspondence: Giulio Peretti, SIOOT Oxygen Ozone Therapy Scientific Society, Via Don Luigi Sturzo 2, 24020 Gorle (BG), Italy. E-mail: info@ossigenoozono.it

Key words: Shoulder adhesive capsulitis; oxygen ozone therapy.

Received for publication: 14 December 2017.

Accepted for publication: 20 December 2017.

(C) Copyright G. Peretti, 2017

Licensee PAGEPress, Italy

Ozone Therapy 2017; 2:7245

doi:10.4081/ozone.2017.7245

This article is distributed under the terms of the Creative Commons Attribution Noncommercial License (by-nc 4.0) which permits any noncommercial use, distribution, and reproduction in any medium, provided the original author(s) and source are credited. normal radiographic tests, except for the possible finding of osteopenia or calcific tendinitis. ${ }^{1}$ It is a condition with an uncertain etiology, characterized by the spontaneous onset of pain.

It is one of the most common and yet less understood pathologies of the glenohumeral joint; this is linked to the fact that there is difficulty in defining it and clearly differentiating it from other conditions with similar symptoms and signs, but with clearly different causes.

It occurs in $2-5 \%$ of the general population, ${ }^{2-4}$ predominantly among women, most commonly between the ages of 40 and 60.5-7

Commonly, this pathology is considered as a self-limiting condition with a natural history that lasts from 1 to 3 years ${ }^{8}$ in some cases, however, a refractory course is reported, with persistent pain and/or movement limitation, in $15-50 \%$ of patients undergoing conservative treatment. ${ }^{9,10}$

\section{Classification}

It is commonly divided into a primitive (idiopathic) and a secondary form. Recently, a post-surgical and post-traumatic variety has been added to these two types ${ }^{11,12}$ (Table 1).

The primitive form includes all cases in which the origin cannot be traced to other known causes. These are, therefore, the forms that arise without apparent reason in an otherwise healthy individual. ${ }^{12}$

In the secondary form, rather, we find some predisposing factors or at least the basis of the pathological process. It is thus defined based on the association with a known pathology. This may be intrinsic, extrinsic, or systemic. ${ }^{12}$

The intrinsic cases are based on an internal shoulder injury, such tendonitis or a rotator cuff lesion, a pathology of the long head of the biceps (LHB), calcific tendonitis, and acromioclavicular arthritis. ${ }^{12}$

The extrinsic cases involve structures external to articulation such as fractures of the clavicle, of the humerus, of the scapula, a prolonged immobilization of the upper limb resulting from trauma, ${ }^{12}$ cardiac pathologies, such as ischemic heart disease and myocardial infarction, and pulmonary disease (emphysema, chronic bronchitis, tuberculosis and tumors), ${ }^{12}$ cervical discopathy, ${ }^{7}$ cerebrovascular accidents (CVA) with motor paralysis of the upper limb, ${ }^{13}$ Parkinson's Disease, ${ }^{13}$ cardiac catheterization through the brachial artery, ${ }^{14}$ and cardiac surgery. ${ }^{15}$

The systemic cases report diabetes mellitus as one of the most frequent causes, with a course that is sometimes different from other primitive or secondary forms and with an often incomplete treatment response..$^{5,7,16,17}$ Thyroid dysfunction, particularly hypothyroidism, is also related to this pathology; ${ }^{18}$ even hypoadrenalism, arterial hypertension, and dyslipidemia are concausal factors. ${ }^{19,20}$ 
Finally, the tertiary forms that develop after an operation or a fracture; in particular, post-surgical forms can be more resistant to both conservative and surgical treatment and therefore require greater attention. ${ }^{12}$

Regarding the evolution of the pathology, four stages have been identified by Hannafin and Chiaia Stage 1 occurs in the first three months of the disease, with pain and minimal or no reduction of movement. Arthroscopic evaluation shows diffuse synovitis of the antero-superior capsule; stage 2, or freezing stage, occurs between 3 and 9 months from the onset, and is characterized by pain, with reduction of movement both while awake and while sleeping, with diffuse synovitis at arthroscopy; stage 3, or frozen stage, between 9 and 15 months, is characterized by minimal pain at extreme degrees of movement, which is however considerably reduced and stops stiffly. Arthroscopy shows a thickened, fibrous capsule, without hypervascularization; stage 4, or thawing, occurs between 15 and 24 months with almost negligible pain and with progressive improvement of mobility until completely subsiding (Table 2).

\section{Pathological anatomy}

The articulation of the shoulder is very complex and occurs on several levels.

It is a combination of movements that occur between the glenohumeral and the scapulothoracic joints with a ratio of 2:1.

To allow its complete amplitude, essential for normal functioning of the shoulder, an intrinsic instability is required, ensured by a loose and wide capsule, whose surface area is twice that of the humeral head.

In order to guarantee stability, capsular thickenings are present forming the superior, middle, and inferior (anterior and posterior) glenohumeral ligaments; the rotator cuff tendons reinforce the capsule anteriorly, superiorly and posteriorly.

Upon arthroscopic examination, it is possible to find synovial recesses, in the anterior area between the superior glenohumeral ligament and the middle one, known as the subscapular recess, in the posterior area just slightly deeper than the infraspinatus, is the infraspinatus recess; to its inferior, there is a lower recess that forms a fold similar to a hammock, stretched between the inferior anterior and posterior glenohumeral ligament, most evident upon adduction of the arm.

The loss of laxity and elasticity of capsular ligament tissues, with the loss of capsular recesses, is the basis for the reduction in movement that occurs in adhesive capsulitis.

Unfortunately, the etiology and the pathophysiological mechanism leading to the onset of this pathology are not well known. ${ }^{22-24}$

The primary sites of localization of the pathological process in adhesive capsulitis are the capsular tissue of the rotator cuff interval, with the coracohumeral ligament, and the axillary recess; there is precisely a thickening and a retraction of these structures; subsequently, the process may extend to the whole capsule. $6,25,26$

Likely there is a progressive pathological process, from a synovial inflammation to capsular fibrosis, where the former is responsible for pain and the second for the reduction of movement with stiffness. ${ }^{22,27-29}$ Rodeo et al. ${ }^{27}$ report that a hypervascular synovial hyperplasia is present in the initial phases, and results in a possible fibrosis of the subsynovial layer and of the capsule.

Recently, in vitro studies, in which samples from patients with adhesive capsulitis have been used, have focused on determining both the immunological basis for the development of the pathology and the role of cell signals and mediators of inflammation in its development. $6,27,28,29$

However, at the moment, there is little understanding of the etiology and the pathological mechanisms underlying the process.

Kim et al., ${ }^{4}$ in a study on rats of 2016, reproduced the onset of adhesive capsulitis by immobilizing the shoulder of the animals for three days, with a molded plaster apparatus, 1, 2, 3, 4, 5, 6 weeks, sacrificing them sequentially and analyzing the samples of the capsule to have an exact verification of the development process of adhesive capsulitis.

After one week, there was already a reduction in the angle of adduction; from a histological point of view, after only three days, the disappearance of the synovial folds, and of the subsynovial adi-

Table 1. Classification of Adhesive capsulitis.

\begin{tabular}{|c|c|c|}
\hline \multicolumn{3}{|c|}{ Adhesive capsulitis } \\
\hline Primitive (idiopathic) & \begin{tabular}{l|l} 
Secondary (known causes) & Tertiary (p \\
\end{tabular} & t-surgical, post-fracture) \\
\hline $\begin{array}{l}\text { Intrinsic } \\
\text { 1.Tendinitis or lesion of } \\
\text { rotator cuff } \\
\text { 2.Tendinitis of LHB } \\
\text { 3.Calcific tendinitis } \\
\text { 4.Acromioclavicular arthrosis }\end{array}$ & $\begin{array}{l}\text { Extrinsic } \\
\text { - Cardio-pulmonary pathology } \\
\text { - Cervical discopathies } \\
\text { - Fractures of the clavicle, humerus, or scapula } \\
\text { - Prolonged immobilization of the upper limb } \\
\quad \text { following trauma } \\
\text { - Cerebrovascular accidents (stroke) } \\
\text { - Parkinson's Disease } \\
\text { - Cardiac catheterization } \\
\text { - Cardiac surgery }\end{array}$ & $\begin{array}{l}\text { Systemic } \\
\text { - Diabetes mellitus } \\
\text { - Hypothyroidism } \\
\text { - Hyperthyroidism } \\
\text { - Adrenal Hypofunction } \\
\text { - Arterial hypertension } \\
\text { - Dyslipidemia } \\
\text { - Epilepsy (phenobarbital } \\
\text { therapy) }\end{array}$ \\
\hline
\end{tabular}


pose tissue, infiltration of inflammatory cells, proliferation of capillaries in the subosynovial tissue, and capsular thickening was noted. After one week, the subsynovial adipose tissue had almost disappeared and the capsular thickening was beginning to be visible. At two weeks, the synovial and subsynovial tissue facing the humerus adhered to the bone, while the infiltration of the inflammatory cells, still present, was however diminished, and the fibrosis was dominant. Masson's trichrome stain showed that fibrosis began after three days and reached maturity at three weeks. There is, therefore, an initial phase of inflammation, with cell infiltration that is reduced after two weeks, while fibrosis progressively grows, reaching its peak after three weeks.

Histological and immunohistochemical examination of biopsy samples taken shows vascularized tissue and collagen with high cellularity, mainly composed of fibroblasts and myofibroblasts; this process is very similar to what occurs in the Dupuytren's contracture of the hand. ${ }^{30}$

A 2013 study by Lho et al., ${ }^{22}$ highlights the increase in inflammatory cytokines (IL-a, TNF-a), of COX-2 in both the joint capsule, and the subacromial recess, while TNF-a and IL-6 were increased in the joint fluid.

The high incidence of adhesive capsulitis in diabetic patients has given rise to speculative hypotheses on the biochemical rationale behind the process. High blood glucose levels are thought to lead to a faster rate of collagen glycosylation and cross-linking into the capsule, which would also underlie Dupuytren's contracture, which also has a high incidence in diabetic patients. ${ }^{31,32}$

\section{Clinical and diagnostic evaluation}

The majority of patients with adhesive capsulitis are referred to a Doctor after weeks or months after the beginning of symptoms, normally when function starts to decrease significantly.

The onset is always insidious, usually progressive, sometimes after a somewhat moderate trauma or effort.

The pain is mainly nocturnal, making it hard to find a comfortable position, and is resistant to treatment with non-steroidal antiinflammatory drugs.

Upon objective examination, there is a limitation of the anterior elevation, which does not exceed $120^{\circ}$ (Figure 1), while the external rotation is reduced by half (Figure 2). Upon palpation, there may be tenderness to pressure of the anterior capsule (particularly at the rotator cuff interval), posterior capsule, and the distal insertion site of the deltoid on the humerus.

The diagnosis is preeminently clinical and is easily reached with the medical history and particularly with the objective examination. From a testing point of view, it is important to perform an $\mathrm{X}$-ray to exclude the presence of glenohumeral arthrosis, which can limit the amplitude of the movement, or a posterior dislocation, which also blocks external rotation, and a good part of any front elevation. Traditional radiology will also provide useful information on the presence of osteopenia, ${ }^{33}$ calcifications in the

Table 2. Stages of Adhesive capsulitis.

Stage 1: Pain; first three months of illness

Stage 2: Freezing; 3-9 months from the onset

Stage 3: Frozen; between 9 and 15 months

Stage 4: Thawing; between 15 and 24 months

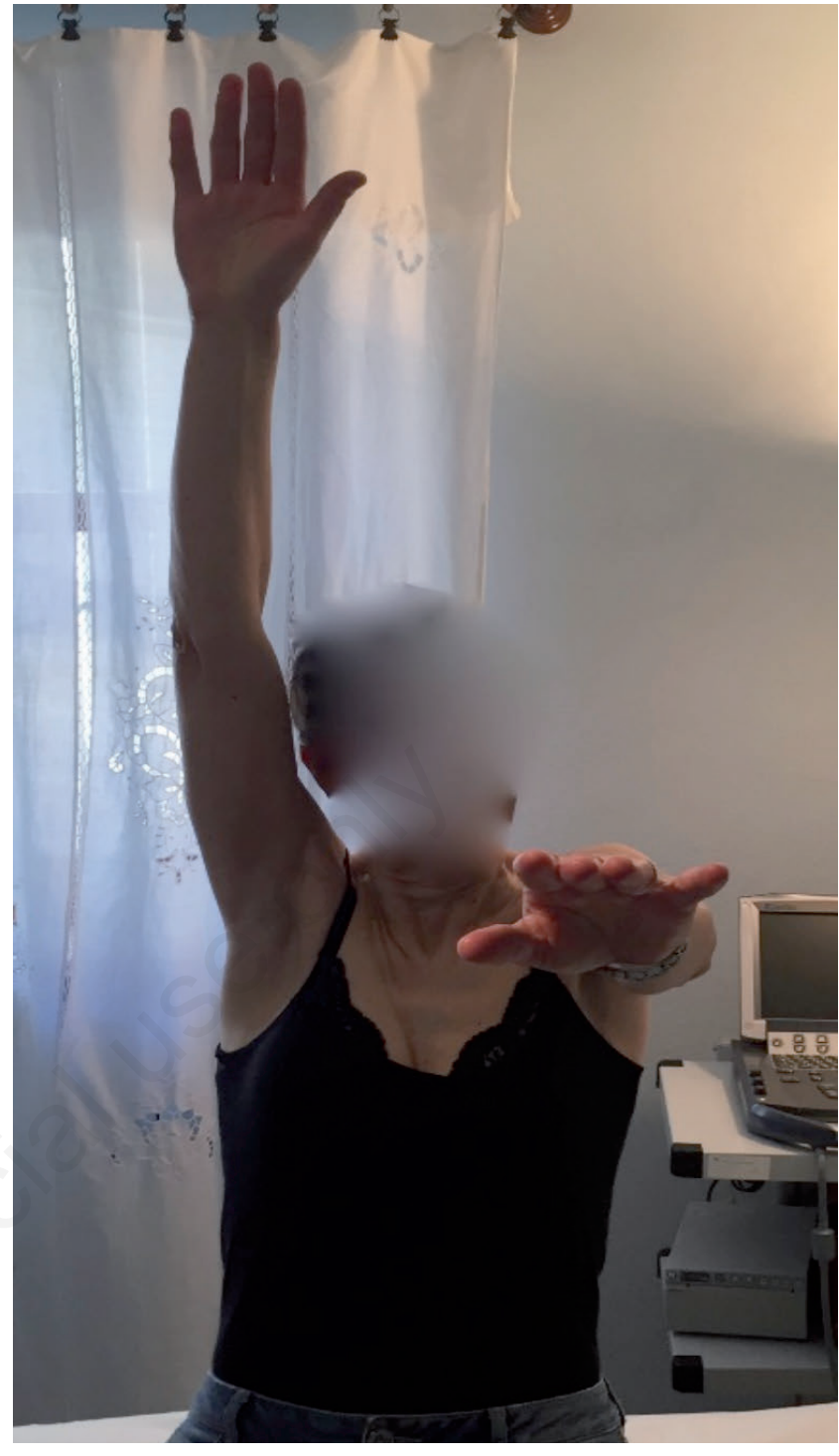

Figure 1. Front elevation reduced on the left.

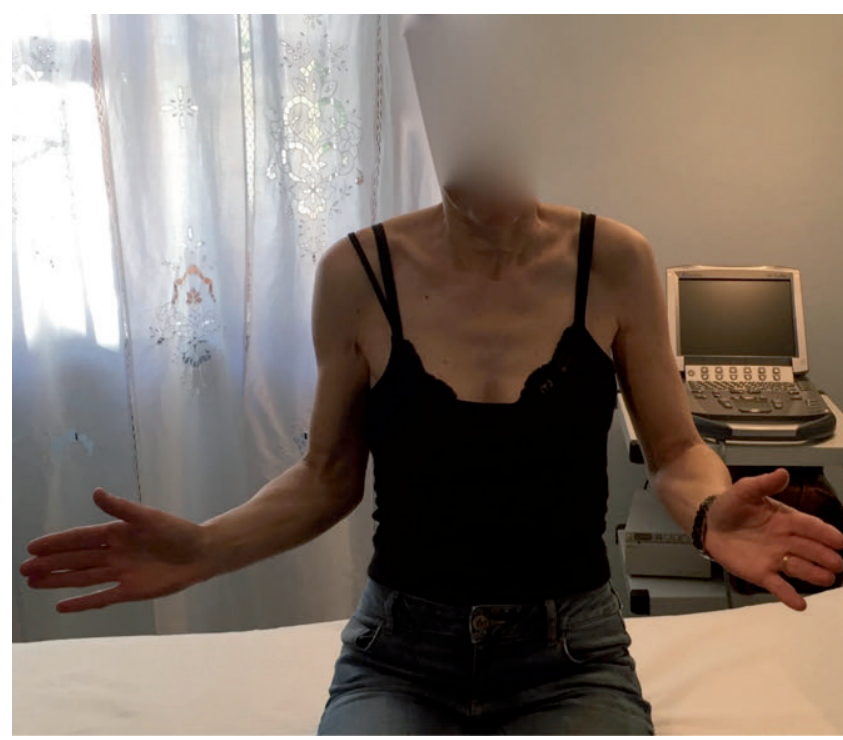

Figure 2. External rotation reduced on the left. 
rotator cuff, a humeral-acromial conflict, or acromioclavicular arthritis.

Another useful test is the Magnetic Resonance that can reveal the presence of injuries of the tendons of the cuff, tendinopathy of the long head of the biceps, synovitis, or intraarticular effusion. It will also be possible to highlight the presence of any thickening of the joint capsule typical of the more advanced stages of capsulitis. ${ }^{34}$ Any artro-MR will demonstrate, with greater precision, the reduction of capsular volume, particularly of the axillary recess. ${ }^{35,36}$

\section{Treatment}

Traditional treatment of adhesive capsulitis involves conservative therapy, followed by more invasive procedures in resistant cases (Table 3). The level of evidence of the various studies is however limited, due to the difficulty in defining etiology with certainty, and the fact that the patients seek treatment at various stages of the disease. The purpose of the various treatments is, however, to eliminate pain and recover movement, therefore acceptable function, within the shortest possible time.

Among conservative treatments there are non-steroidal antiinflammatory drugs; however, a significant effect in improving pain and function has never been demonstrated.

The use of oral corticosteroids has shown a significant reduction of pain, particularly at night, and rapid recovery of movement. ${ }^{37-39}$

Intrarticular or subacromial area infiltration is commonly used, with results comparable to physiotherapy or more invasive measures such as manipulation under anesthesia or capsule hydrodilatation. ${ }^{40-42}$

Physiotherapy and stretching are universally accepted in the conservative treatment of such pathology, with good results in terms of resolution of symptoms. ${ }^{43}$

Hydrodilatation also seems to offer excellent results, better than manipulations for release under anesthesia, which involve a greater amount of time. ${ }^{44}$

Recent work on the use of acupuncture in adhesive capsulitis shows good results at three months on the recovery of articulation, above all elevation, and adduction, and on the Visual Analogue Scale of pain. ${ }^{45}$

Among invasive treatments we find manipulation under anesthesia, and surgical release.

Release under anesthesia consists in carrying out manipulations of the joint under general anesthesia, in order to free the movement of the shoulder. During manipulation there is a perception of a breakdown of tissues, very similar to the sensation felt when a Velcro is torn. Comparative studies, however, did not show

Table 3. Treatments of Adhesive capsulitis.

\begin{tabular}{ll} 
Conservative treatment & Non-invasive treatment \\
NSAIDs & Manipulation under anesthesia \\
Oral corticosteroid therapy & Release under arthroscopy \\
\hline Corticosteroid infiltrations & Surgical release \\
Physiotherapy & \\
\hline Hydrodilatation & \\
Acupuncture & \\
\hline
\end{tabular}

significant benefits compared to patients treated with physiotherapy ${ }^{46}$ or hydrodistension. ${ }^{44}$ On the contrary, with such treatment, complications such as fractures of the humerus, fractures of the glenoid, lesions of the ligaments, or avulsion of the glenoid, or injuries of the tendons of the cuff are common, thus this method is currently not recommended.

Arthroscopic capsular release is currently the treatment of choice in cases resistant to conservative therapy; this allows, after careful inspection and under direct control, a $360^{\circ}$ capsular release, with the release of the thickened and retracted parts. Then there will be an immediate recovery of movement, and resolution of the painful symptoms. Further, such treatment also allows highlighting lesions associated with tendons or intra-articular structures with the possibility of proceeding to their treatment (Figure 3 ).

Traditional open air surgical treatment has now been superseded by the arthroscopic technique that allows for a better evaluation and complete $360^{\circ}$ treatment.

\section{Treatment with oxygen-ozone: rationale, technique}

Oxygen-ozone treatment, which uses a mixture of $95-96 \%$ oxygen and $4-5 \%$ ozone, can be useful in different forms of adhesive capsulitis. As we have seen earlier, in this pathology there is a phase of inflammation of the joint capsule, with intense pain, which progresses with fibrosis of the same (very similar to that present in Dupuytren's contracture); the latter causes tissue retraction with reduction of shoulder articulation.

Among the various actions of ozone, there is a modulation and reduction of inflammation activity, and a reduction of pain with various mechanisms. Local injection of oxygen-ozone inactivates and destroys algogenic substances (oxidizing prostaglandins), inactivates bradykinin and other peptides, alters the serotonin, which has an indole nucleus, produces degradation of extracellular

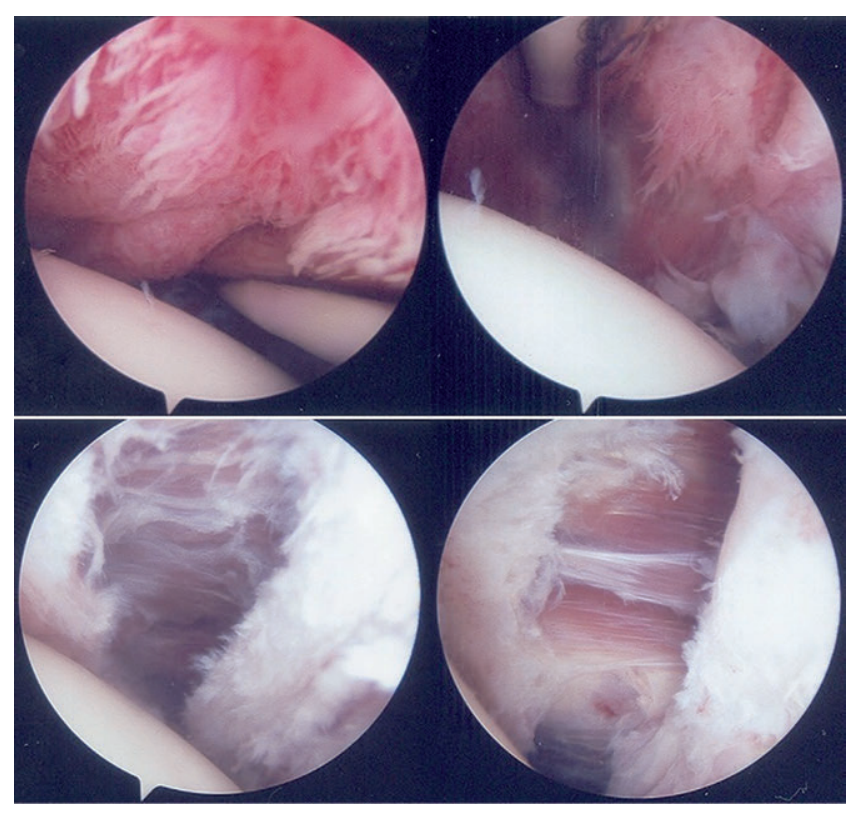

Figure 3. Top boxes: hyperemia and capsular retraction; bottom boxes: outcome of the release with opening of the capsule and viewing of the underlying subscapularis muscle. 
ATP, and transforms interleukins. All the above-mentioned substances are then modified so that they can no longer produce pain. There is also a release of antagonists, or soluble receptors, which neutralize proinflammatory cytokines, such as interleukins (IL-1, IL-2, IL-8, IL-12, IL-15), interferon-a, and TNF-a.

Finally, the denaturation of cellular proteins that produce algogenic substances such as COX, kininogen, kallikrein, occurs. It also modifies pain receptors and forms endorphins onsite.

Another activity of considerable importance is given by the decontracting and muscle relaxant action by direct action on the muscle fibers. ${ }^{47-51}$

Based on these assumptions, therefore, its use in the treatment of adhesive capsulitis is appropriate.

Pregnancy, latent hypoglycemia, hyperthyroidism, favism and sickle cell anemia, were considered for contraindications to treatment. It was also evaluated whether any lipomas were present in the areas to be treated due to the risk of embolism caused by the presence of arteriovenous shunts in such neoformations.

All patients were informed about the type of treatment, the characteristics of oxygen-ozone therapy, possible complications, therapeutic alternatives, and signed a consensus.

With regard to technique, Oxygen-Ozone Multiossigen Medical 99 I.R. Equipment was used (EC Marked by a Body notified by the Ministry of Health pursuant to Directive 93/42/EEC as amended and supplemented, Italian Legislative Decree 46/97 as amended and supplemented in class 2 A) (Figure 4).

Regarding Ozone concentrations and methods of administration, strict compliance with the protocols issued by the SIOOT [Oxygen Ozone Therapy Scientific Association), was implemented.

A $10 \mathrm{cc}$ syringe, a $30-\mathrm{mm} 23 \mathrm{G}$ needle, and a 4-mm 30G needle were used for collection and administration (Figure 5). In each ses-

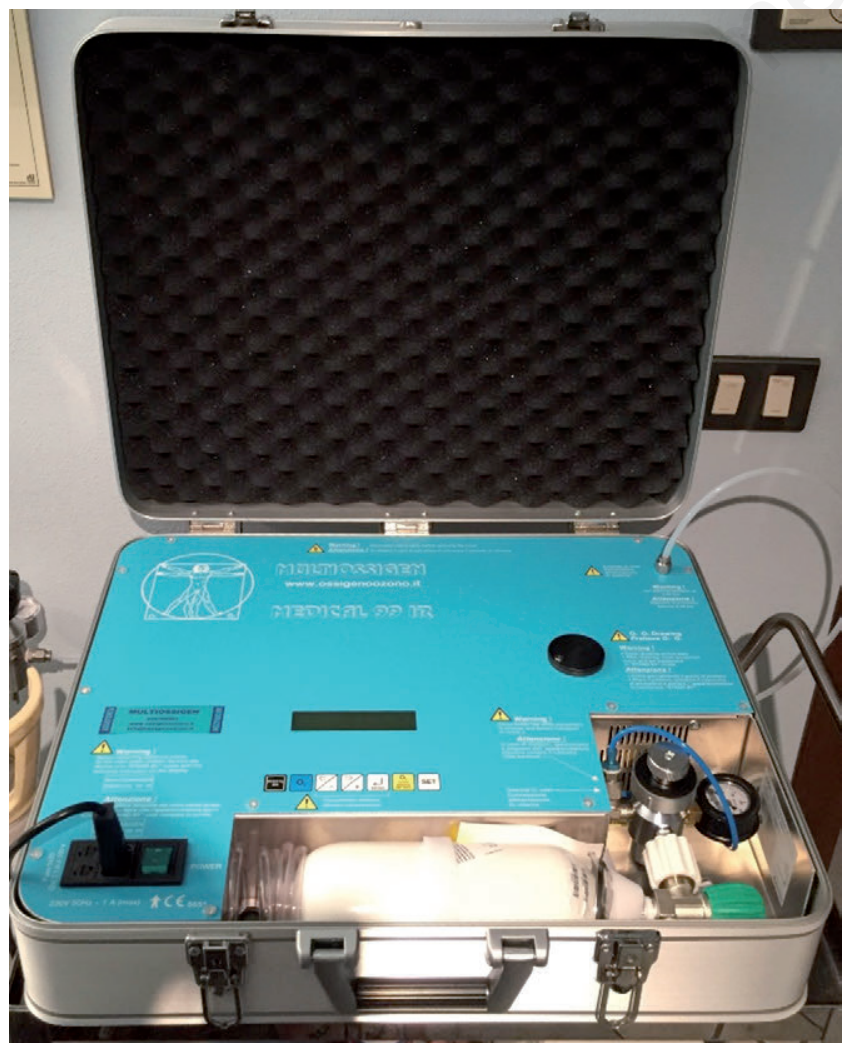

Figure 4. Oxygen-ozone therapy equipment. sion, intra-articular infiltration and multiple subcutaneous infiltrations were performed at pre-established points. Eight to ten sessions were performed with a frequency of one per week.

For intra-articular infiltrations, the posterior access was used (Figure 6), after thorough disinfection with povidone-iodine solution, with a $30 \mathrm{~mm} 23 \mathrm{G}$ needle. The dosage used in the first session was $7 \mathrm{mg} / \mathrm{ml}$, infiltrating $7 \mathrm{cc}$. In the following sessions, $10 \mathrm{mg} / \mathrm{ml}$ were used, always infiltrating $7 \mathrm{cc}$, and gradually increasing to $15 \mathrm{mg} / \mathrm{ml}$.

Subcutaneous infiltrations were performed on predetermined points (Figure 7A and B), where pain and tenderness are usually reported. For this purpose a $4 \mathrm{~mm} 30 \mathrm{G}$ needle was used, infiltrating 3-5 cc per point for a total of $20-40 \mathrm{cc}$ per session. At the end of the infiltrations, a massage was performed, with ozonized cream, in order to obtain a good diffusion and deep penetration of the ozone.

\section{Patients}

From March 2015 to March 2016, 10 patients with adhesive capsulitis were treated with a cycle of intra-articular and subcutaneous infiltrations.

Of these, 6 patients were female, of 49.3 average age (min 40 - $\max 59)$ and 4 males, of 56.7 average age ( $\min 48$ - $\max 65)$; the average age of all participants was 52.3 ( $\min 40$ - max 65). The dominant limb was affected in seven cases, while in three, the nondominant limb was affected.

Regarding the etiology in three subjects it was a primitive form, in one case, it was secondary in a diabetic subject, in one patient it was secondary to calcific tendinitis in diabetes, in another patient it was secondary to calcific tendinitis, subjected to two ultrasound-guided percutaneous lithotrophic sessions in cervicalgia and fibromyalgia, in four patients it was persistent capsulitis

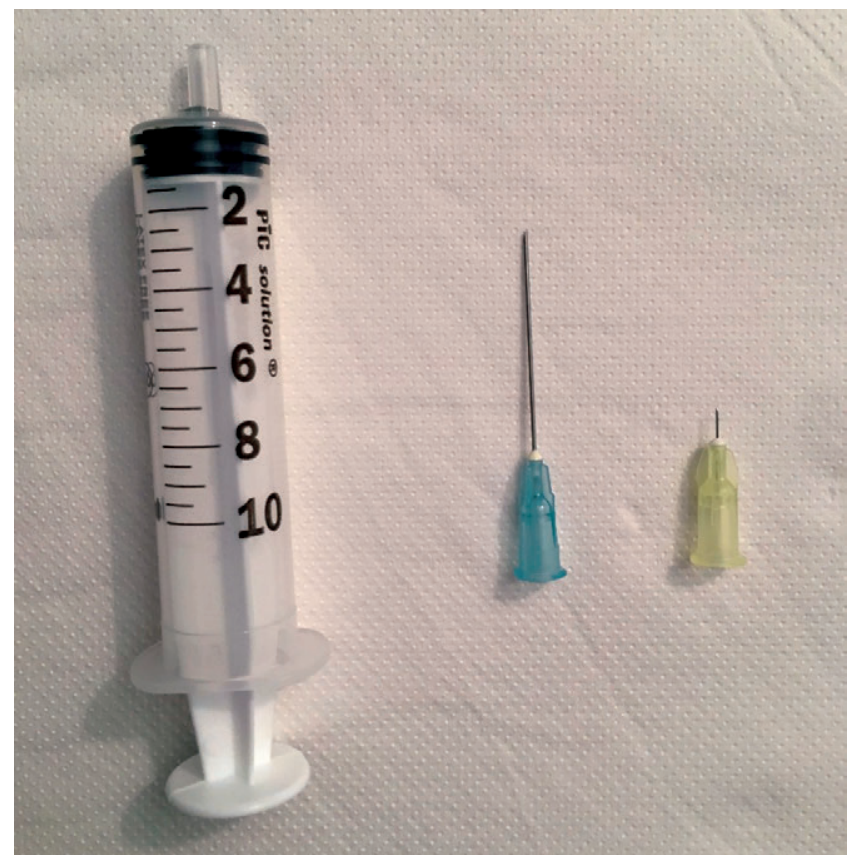

Figure $5.10 \mathrm{cc}$ syringe and $30 \mathrm{~mm}$ with $23 \mathrm{G}$ needle, and $4 \mathrm{~mm}$ with $30 \mathrm{G}$ needle was used. 
after arthroscopic arthrolysis in diabetic patients, of which a female subject underwent arthrolysis and removal of intramedullary nail in fracture sequelae of the $3 \mathrm{rd}$ medial humerus, suffering from insulin-dependent diabetes (Table 4).

Subjects were assessed at the beginning of treatment, at the end and six months after the end of treatment (Table 4). In the evaluation the Visual Analogue Scale (Figure 8) for pain and the Constant score (Table 5), normalized by age, sex and side (Table 6), for the overall assessment of the shoulder. ${ }^{52}$

It is interesting to note that before treatment, the pain was strong, settling on an average value of 8 on the VAS scale, with a low Constant score of 32.5 ( $\min 26.6$ - $\max 38.8$ ), while at the end of the treatment, the value of the VAS scale had fallen to 1.9 with a Constant score of 74.7 ( $\min 68.8$ - max 78.4). After six months from the end of treatment, there was a further improvement with a regression of painful symptoms, VAS 1, and remarkable recovery of functionality, Constant score 92.4 ( $\min 82.3$ - $\max 98.6$ ).

No significant complications occurred in this group of patients. The only adverse event was the onset of significant pain, in the first few minutes after intra-articular infiltration, in the first two to three sessions, but which subsided after about five minutes.

\section{Discussion}

Adhesive capsulitis is a very complex and insidious pathology, highly disabling for patients, who also experience very intense pain symptoms. Pain significantly reduces the quality of life, manifesting itself insistently during rest periods, which are severely disrupted. Work activity is compromised with further significant damage.

Although it is a pathology that tends to resolve spontaneously, its duration is still long reaching over 24-30 months, with a subsequent persistence of symptoms, with regard to pain and limitation of movement, which may affect $15-50 \%$ of subjects.

The execution of an effective therapy is therefore essential to shorten the period of the disease and reduce any residual consequences as much as possible.

Among the various treatments available to us, oral or infiltrative corticosteroid therapy, as we have seen, can provide excellent results. However, it must be considered that it can still have significant side effects and it is not always well-tolerated by patients. Moreover, often patients with diabetes will incur greater difficulties and risks in carrying out both the oral and infiltrative treatment. Their use can in fact cause decompensation with an increase in glucose values; in infiltrative therapy, in addition to the previ-

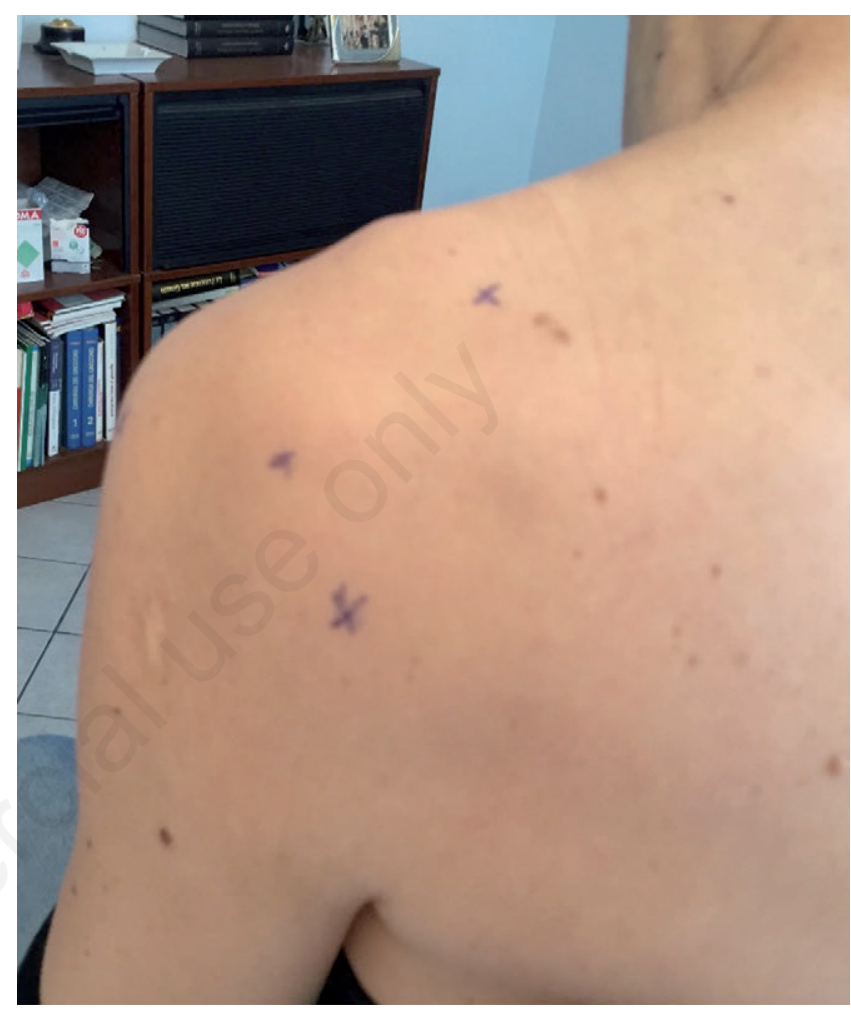

Figure 6. Posterior access.

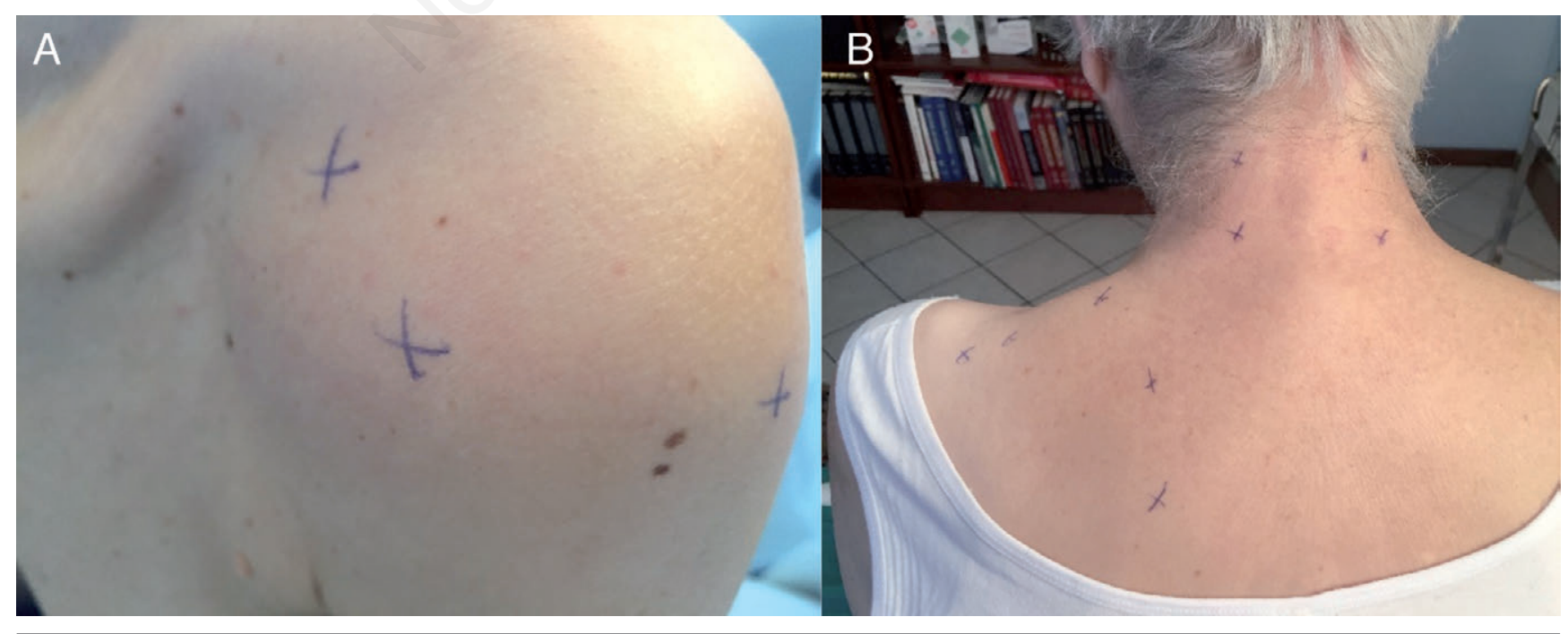

Figure 7. A) anterior and lateral subcutaneous points; B) posterior subcutaneous points. 
ously mentioned issue, there will also be an increased risk of the onset of joint infections. Moreover, often, when treatment is discontinued, symptoms can relapse.

Physiotherapy can be an effective treatment, with good results reported in medical literature, nevertheless, particularly in the early stages where pain and inflammation are greater, it is difficult to implement. In fact, the attempt to mobilize accentuates the pain symptoms and, due to a reflex arc, very often increases inflammation and consequent stiffness. We believe it can be very useful, but during a second phase, when pain and inflammation have already been reduced and, in any case, with concomitant treatments.

Acupuncture, which has no side effects and improves symptoms, also seems to provide promising results. Further studies are therefore needed to validate its usefulness.

Arthrolysis and arthroscopy release provide excellent results for pain resolution and recovery of movement, particularly in

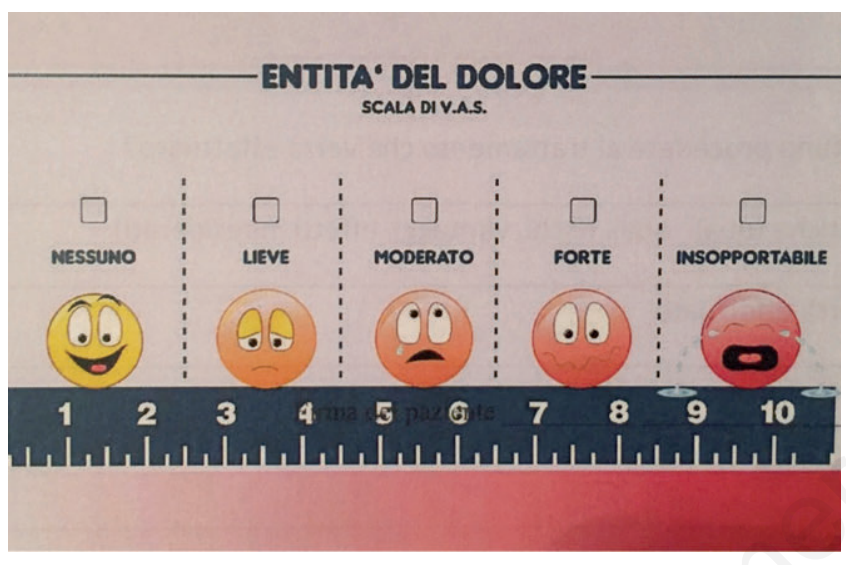

Figure 8. VAS pain scale. primitive forms. However, this is an invasive treatment that cannot be used as an initial treatment. Furthermore, particularly in surgical sequelae and in diabetic patients, it may sometimes be difficult to achieve complete recovery.

In my case studies, particularly in diabetic patients and in one post-surgical fracture case, there was a persistence of pain and stiffness.

Even as shown in medical literature, post-traumatic and postsurgical cases are always the most difficult to treat. In the abovementioned cases, in fact we face retractions of very significant tissues, with persistent residual inflammation, nuanced frameworks of algoneurodystrophy and latent neurological pain.

In many cases there is also chronic pain, in trauma, surgery, and prolonged immobilization sequelae, with alteration of pain receptors.

In diabetic patients, progression is always complicated, with a high incidence of recurrence or persistence of pain, with resistance to treatment.

Another important fact, which is constantly found, is the presence of a considerable muscle contracture, with pain and tenderness upon palpation, affecting the trapezius, the levator scapulae muscle, small and large rhomboids and the cervical and dorsal paravertebral muscles. This can be linked to a postural alteration, a protective tendency, and an increased tension that leads to keeping the muscles in contraction mode. This fact contributes to feeding and accentuating the pain.

The use of ozone, thanks to its ability to reduce and modulate inflammation, to destroy the algogenic substances, to modify pain receptors, to improve microcirculation, and to produce a muscle relaxant action, has allowed to greatly improve the symptoms and the functionality of shoulders in such patients, allowing for a faster recovery and return to activities.

The analysis of the case studies shows us that there was a considerable reduction in pain already at the end of the treatment, which was subsequently maintained at the six-month follow-up, as evidenced by the analysis of the Visual Analogue Scale for pain.

The improvement of the Constant score also shows that there

Table 4. Patients.

\begin{tabular}{|c|c|c|c|c|c|c|c|c|c|}
\hline $\begin{array}{l}\text { Subject } \\
\text { Sex } \\
\text { Side }\end{array}$ & Age & Etiology & $\begin{array}{l}\text { No. of } \\
\text { Sessions }\end{array}$ & $\begin{array}{l}\text { Costant } \\
\text { initial } \\
\text { score }\end{array}$ & $\begin{array}{l}\text { Initial } \\
\text { VAS }\end{array}$ & $\begin{array}{l}\text { End of } \\
\text { treatment } \\
\text { Costant } \\
\text { score }\end{array}$ & $\begin{array}{l}\text { End of } \\
\text { treatment } \\
\text { VAS }\end{array}$ & $\begin{array}{l}\text { 6-month } \\
\text { Costant } \\
\text { score }\end{array}$ & $\begin{array}{l}\text { VAS at } \\
6 \\
\text { months }\end{array}$ \\
\hline 1 F Right & Age: 59 & Primitive & 10 & 36.6 & 9 & 74.6 & 2 & 98.6 & 1 \\
\hline 2 F Left & Age: 55 & Primitive & 10 & 33.8 & 8 & 76 & 1 & 97.1 & 1 \\
\hline 3 F Left & Age: 43 & Primitive & 10 & 28.2 & 9 & 78.4 & 3 & 93.6 & 1 \\
\hline 4 M Left & Age: 48 & Diabetes & 10 & 28.1 & 8 & 68.8 & 2 & 85.4 & 1 \\
\hline 5 F Right & Age: 54 & $\begin{array}{l}\text { Calcific tendinitis, percutaneous lithotripsy, } \\
\text { cervicalgia, fibromyalgia }\end{array}$ & 10 & 26.6 & 9 & 77.3 & 2 & 93.3 & 1 \\
\hline 6 F Right & Age: 40 & Calcific tendinitis, diabetes & 8 & 33.3 & 8 & 73.3 & 2 & 94.4 & 1 \\
\hline 7 M Right & Age: 65 & Persistent after arthrolysis in diabetes & 10 & 31.3 & 9 & 73.5 & 2 & 89.1 & 1 \\
\hline 8 M Right & Age: 52 & Persistent after arthrolysis in diabetes & 10 & 31.9 & 6 & 69.1 & 2 & 93.6 & 1 \\
\hline 9 M Right & Age: 62 & Persistent after arthrolysis in diabetes & 8 & 36.1 & 7 & 78.3 & 2 & 96.3 & 1 \\
\hline 10 F Right & Age: 45 & $\begin{array}{l}\text { Persistent after arthrolysis and removal of the nail } \\
\text { in sequelae of a humeral fracture } \\
\text { in insulin-dependent juvenile diabetes }\end{array}$ & 8 & 38.8 & 7 & 77.6 & 1 & 82.3 & 1 \\
\hline Average value & $\begin{array}{l}52.3 \\
(\min 40- \\
\max 65)\end{array}$ & & & $\begin{array}{c}32.5 \\
(\min 26.6- \\
\max 38.8)\end{array}$ & $\begin{array}{c}8 \\
(\min 6- \\
\max 9)\end{array}$ & $\begin{array}{c}74.7 \\
(\min 68.8- \\
\max 78.4)\end{array}$ & $\begin{array}{c}1.9 \\
(\min 1- \\
\max 3)\end{array}$ & $\begin{array}{l}92.4 \\
(\min 82.3- \\
\max 98.6)\end{array}$ & 1 \\
\hline
\end{tabular}


was an essentially complete functional recovery from an initial value of 32.5 to a final value of 92.4 .

Another important fact is that, in addition to very low-level invasion, there were no significant side effects. This fact made the treatment very well-tolerated by patients.

This study has many limitations because it is a limited case study, and extremely inhomogeneous. However, it can be the basis on which to carry out more targeted studies, on a greater number of patients and with better scientific and statistical criteria. This study has indeed made it possible to demonstrate the effectiveness and safety of this method, which could allow its use on a larger scale.

Table 5. Constant score.

\begin{tabular}{lc}
\hline Item & Score \\
\hline Pain & 15 \\
None & 15 \\
Mild & 10 \\
Moderate & 5 \\
Severe & 0 \\
Activities of daily living & 20 \\
Full work & 4 \\
Full recreation/sports & 4 \\
Unaffected sleep & 2 \\
Hand position & \\
$\quad$ up to waist & 2 \\
$\quad$ up to xiphoid & 4 \\
$\quad$ up to top of head & 8 \\
$\quad$ above head & 10 \\
Range of motion & 40 \\
Abduction & 10 \\
Forward elevation & 10 \\
Int. rotation & 10 \\
Ext. rotation & 10 \\
Shoulder power & 25 \\
Pounds to resist & 100 \\
Total &
\end{tabular}

Table 6. Constant score normalized by age, sex, and side.

\begin{tabular}{|c|c|c|c|c|c|c|c|c|}
\hline \multirow[b]{2}{*}{ Age } & \multicolumn{4}{|c|}{ Male subjects } & \multicolumn{4}{|c|}{ Female subjects } \\
\hline & Right & Left & Mean & SD & Right & Left & Mean & SD \\
\hline & 97 & 99 & 98 & & & & & \\
\hline $31-40 y$ & 97 & 90 & 93 & 3.4 & & 91 & 90 & 4.1 \\
\hline $41-5$ & 86 & 96 & 92 & 3.6 & 8 & 78 & 80 & 3.8 \\
\hline $51-60 y$ & 94 & 87 & & 3.1 & & 71 & 73 & 2.8 \\
\hline $61.70 y$ & 83 & 83 & 83 & 4.2 & 70 & 68 & 70 & 4.0 \\
\hline $71-80 y$ & 76 & 73 & 75 & 3.6 & 71 & 64 & 69 & 3.9 \\
\hline $81-90 y$ & 70 & 61 & 66 & 3.1 & 65 & 64 & 64 & 2.9 \\
\hline $91-100 y$ & 60 & 54 & 56 & 4.3 & 58 & 50 & 52 & 5.1 \\
\hline
\end{tabular}

\section{Conclusions}

Oxygen-ozone treatment in adhesive capsulitis proved to be extremely effective; the absence of side effects has proven the safety of its use. A comparison with other types of treatment demonstrates a similar, and perhaps greater efficacy with no risks and side effects such as are present in the others.

A fundamental aspect is the use of equipment certified and recognized by the Ministry for the production of oxygen-ozone, compliance with the protocols of the SIOOT, and scrupulousness in the execution of infiltrations as regards a sterile environment and the type of material used.

Further studies are necessary to confirm the validity of this technique.

\section{References}

1. Zuckerman JD, Rokito A. Frozen shoulder: a consensus definition. J Shoulder Elbow Surg 2011; 20: 322-325.

2. Hand GC, Athanasou NA, Matthews T, Carr AJ. The pathology of frozen shoulder. J Bone Joint Surg (B). 2007;89(7):928-932.

3. Sheridan MA, Hannafin JA. Upper extremity: emphasis on frozen shoulder. Orthop Clin North Am. 2006;37(4):531-539.

4. Kim DH, Lee KH, Lho YM, Ha E, Hwang I, Song KS, Cho $\mathrm{CH}$. Characterization of a frozen shoulder model using immobilization in rats. J Orthopaedic Surg res. 2016;11:160-165.

5. Boyle-Walker KL, Gabard DL, Bietsch E, Masek-Van-Arsdale DM, Robinson BL. A profile of patients with adhesive capsulitis. J Hand Ther. 1997;10:222-228.

6. Hand GCR, Athanasou NA, Matthews T, Cart AJ. The pathology of frozen shoulder. J Bone Joint Surg Br. 2007;89:928-932.

7. Wright V, Haq AM. Periarthritis of the shoulder. I. Aetiological considerations with particular reference to personality factors. Ann Rheum Dis. 1976;35:213-219.

8. Rizk TE, Pinals RD. Histocompatibility type and racial incidence in frozen shoulder. Arch Phys Med Rehabil. 1984;65:33.

9. Shaffer B, Tibone JE, Kerlan RK. Frozen shoulder. A longterm follow-up. J Bone Joint Surg Am.1992;74:738-746.

10. Hand C, Clipsham K, Rees JL, Carr AJ. Long-term outcome of frozen shoulder. J Shoulder Elbow Surg Am. 2008;17:231-236.

11. Lundberg BJ. The frozen shoulder: clinical and radiographical observations: The effect of manipulation under general anesthesia: Structure and glycosaminoglycan content of the joint capsule. Acta Orthop Scand (Suppl) 1969;119:1-59.

12. Cuomo F, Brian Holloway G. Diagnosi e trattamento della spalla rigida. In Iannotti JP, Williams GR JR. Patologie della Spalla. Diagnosi e trattamento. Verduci editore; seconda edizione; Vol. 1:529-547.

13. Sullo L. Patologia dolorosa del cingolo scapolare nell'ambito dello stroke e della malattia di Parkinson. In Peretti G. Spalla Neurologica. Timeo Editore 2012;31-46.

14. Pineda C, Arana B, Martinez-Lavin M, Dàbague J. Frozen shoulder triggered by cardiac catheterization via the brachial artery. Am J Med 1994;96:90-91.

15. Tuten HR, Young DC, Douoguih WA, Lenhardt KM, Wilkerson JP, Adelaar RS. Adesive capsulitis of the shoulder in male cardiac surgery patients. Orthopedics 2000;23:693-696.

16. Arkkila PT, Kantola IM,Viikari JA, Rönnemaa T. Shoulder capsulitis in type I and II diabetic patients: association with diabetic complications and related diseases. Ann Rheum Dis 1996;55:907-914. 
17. Thomas SJ, McDougall C, Brown ID, Jaberoo MC, Stearns A, Ashraf R, et al. Prevalence of symptoms and signs of shoulder problems in people with diabetes mellitus. J Shoulder Elbow Surg 2007;16:748-751.

18. Schiefer M, Santos Teixeira PF, Fontenelle C, Carminatti T, Santos DA, Righi LD, Conceição FL. Prevalence of hypothyroidism in patients with frozen shoulder. J Shoulder Elbow Surg 2017;26:49-55.

19. Bunker TD, Esler CN. Frozen shoulder and lipids. J Bone Joint Surg Br 1995;77:684-686.

20. Wolf JM, Green A. Influence of comorbidity on self-assessment instrument scores of patients with idiopathic adhesive capsulitis. J Bone Joint Surg Am2002;84:1167-1173.

21. Hannafin JA, Chiaia TA. Adhesive capsulitis: a treatment approach. Clin Orthop 2000;372:95-109.

22. Lho YM, Ha E, Cho CH, Song KS, Min BW, Bar KC, Lee KJ, Hwang I, Park HA. Inflammatory cytokines are overexpressed in the subacromial bursa of frozen shoulder. J Shoulder Elbow Surg. 2013;22(5):666-672.

23. Sheridan MA, Hannafin JA. Upper extremity: emphasis on frozen shoulder. Orthop Clin North Am. 2006;37(4):531-539.

24. Robinson CM, Seah KT, Chee YH, Hindle P, Murray IR. Frozen shoulder. J Bone Joint Surg Br. 2012;94(1):1-9.

25. Ozaki J, Nakagawa Y, Sakurai G, Tamai S. Recalcitrant chronic adhesive capsulitis of the shoulder: Role of contracture of the coracohumeral ligament and rotator interval in pathogenesis and treatment. J Bone Joint Surg Am. 1989;71(10):1511-1515.

26. Hsu JE, Anakwenze OA, Warrender WJ, Abboud JA. Current review of adhesive capsulitis. J Shoulder Elbow Surg. 2011; 20(3):502-514.

27. Rodeo SA, Hannafin JA,Tom J, Warren RF, Wickiewicz TL. Immunolocalization of cytokines and their receptors in adhesive capsulitis of the shoulder. J Orthop Res. 1997;15(3):427-436.

28. Mullet H, Byrne D, Colville J. Adhesive capsulitis: human fibroblast response to shoulder joint aspirate from patients with stage II disease. J Shoulder Elbow Surg. 2007;16(3):290-294.

29. Bunker TD, Reilly J, Baird KS, Hamblen DL. Expression of growth factors, cytokines and matrix metalloproteinases in frozen shoulder. J Bone Joint Surg Br.2000;82(5):768-773.

30. Hutchinson JW, Tierney GM, Parson SL, Davis TR. Dupuytren's disease and frozen shoulder induced by treatment with a matrix metalloproteinase inhibitor. J Bone Joint Surg Br 1998;80:907-908.

31. Brownlee M, Cerami A, Vlassara H. Advanced glycoylation end products in tissue and the biochemical basis of diabetic complications. N Engl J Med1988;318:1315-1321.

32. Brownlee M, Vlassara H, Cerami A. Nonenzymatic glycosylation and the pathogenesis of diabetic complications. Ann Intern Med 1984;101:527537.

33. Lundberg BJ, Nilsson BE. Osteopenia in the frozen shoulder. Clin Orthop Relat Res 1968;60:187-191.

34. Tamai K, Yamato M. Abnormal synovium in the frozen shoulder: a preliminary report with dinamic magnetic resenance imaging. J Shoulder Elbow Surg 1997;6:534-543.

35. Manton GL, Schweitzer ME, Weishaupt D, Karasick D. Utility of RM arthrography in the diagnosis of adhesive capsulitis. Skeletal Radiol 2001;30:326-330.

36. Mengiardi B, Pfirmann CW, Gerber C, Hodler J, Zanetti M. Frozen shoulder: MR arthrographic findings. Radiology 2004;233:486-492.
37. Binder A, Hazleman BL, Parr G, Roberts S. A controlled study of oral prednisolone in frozen shoulder. $\mathrm{Br} \mathrm{J}$ Rheumatol 1986;25:288-292.

38. Buchbinder R, Green S, Youd JM, Johnston RV. Oral steroids for adhesive capsulitis. Cochrane Database Syst Rev 2006: CD006189.

39. Buchbinder R, Hoving JL, Green S, Hall S, Forbes A, Nash P. Short course prednisolone for adhesive capsulitis (frozen shoulder or stiff painful shoulder): a randomised, double blind, placebo controlled trial. Ann Rheum Dis 2004;63:1460-1469.

40. Jacobs LG, Smith MG, Khan SA, Smith K, Joshi M. Manipulation or intra-articular steroids in the management of adhesive capsulitis of the shoulder? A prospective randomized trial. J Shoulder Elbow Surg 2009;18:348-353.

41. Ryans I, Montgomery A, Galway R, Kernohan WG, McKane R. A randomized controlled trial of intra-articular triamcinolone and/or physiotherapy in shoulder capsulitis. Rheumatology (Oxford) 2005;44:529-535.

42. Tweita EK, Tariq R, Sesseng S, Juel NG, Bautz-Holter E. Hydrodilation, cortcosteroids and adhesive capsulitis: a randomized controlled trial. BMC Musculoskelet Disord 2008;9:53.

43. Miller MD, Wirth MA, Rockwood CA Jr. Thawing the frozen shoulder: The "patient" patient. Orthopedics 1996;19:849-853.

44. Quraishi NA, Johnston P, Bayer J, Crowe M, Chakrabarti AJ. Thawing the frozen shoulder. A randomized trial comparing manipulation under anaesthesia with Hydrodilatation. J Bone Joint Surg Br2007;89:1197-1200.

45. Asheghan M, Aghda AK, Hashemi E, Hollisaz M. Investigation of the effectiveness of acupuncture in the treatment of frozen shoulder. Mater Sociomed 2016 Aug;28 (4):253-257.

46. Kivimaki J, Pohjolainen T, Malmivaara A, Kannisto M, Guillaume J, Seitsalo S et al. Manipulation under anaesthesia with home exercises versus home exercises alone in the treatment of frozen shoulder: a randomized, controlled trial with 125 patients. J Shoulder Elbow Surg 2007;16:722-726.

47. Bocci V. Scientific and medical aspect of ozone therapy. State of the art. Arch Med Res 2006;37:425-435.

48. Paoloni M, Di Sante L, Cacchio A, Apuzzo D, Marotta S, Razzano M, Franzini M, Santilli V. Intramuscolar OxygenOzone therapy in the treatment of acute back pain with lumbar disc herniation. A multicenter, randomized, double-blind, clinical trial of active and simulated lumbar paravertebral injection. Spine 2009;34;13:1337-1344.

49. Ozturk O, Tezcan AH, Adali Y, Yildirim CH, Aksoy O, Yagmurdur H, Bilge A. Effect of ozone and methylprednisolone treatment following crush type sciatic nerve injury. Acta Cirùrgica Brasileira. 2016;31(11):730-735.

50. Bocci V, Zanardi I, Travagli V. Oxygen/ozone as a medical gas mixture. A critical evaluation of the various methods clarifies positive and negative aspects. Medical Gas Research 2011;1-9.

51. Onal O, Yetisir F, Salman Sarer AE, Zeybeck ND, Onal CO, Yurekli BY, Celik HT, Sirma A, Kilic M. Prophylactic ozone administration reduces intestinal mucosa injury induced by intestinal ischemia-reperfusion in the rat. Mediators of inflammation (Hindawi Publishing Corporation) 2015:1-8.

52. Constant CR, Gerber C, Emery RJH, Søjbjerg JO, Gohlke F, Boileau P. A review of the Costant score: Modifications and guidelines for its use. J Shuolder Elbow Surg 2008;17:355-361. 